\title{
ROOFING ASSESSMENT FOR ROOFTOP RAINWATER HARVESTING ADOPTION USING REMOTE SENSING AND GIS APPROACH
}

\author{
N. A. W. M. Radzali, H. Z. M. Shafri ${ }^{*}$, M. Norman, S. Saufi \\ Department of Civil Engineering, Faculty of Engineering, Universiti Putra Malaysia, 43400 Serdang, Selangor, \\ Malaysia - helmi@upm.edu.my
}

KEY WORDS: Remote sensing, GIS, rooftop rainwater harvesting, geospatial environment

\begin{abstract}
:
Rooftop rainwater harvesting refers to the collection and storage of water from rooftops whereby the quality of harvested rainwater depend on the types of roof and the environmental conditions. This system is capable to support the water supply in almost any place either as a sole source or by reducing stress on other sources through water savings. Remote sensing and GIS have been widely used in urban environmental analysis. Thus, this study aimed to develop the roofing layer in order to assess the potential area for rooftop rainwater harvesting adoption by integrating remote sensing and GIS approach. An urban area containing various urban roofing materials and characteristics was selected. High resolution satellite imagery acquired from WorldView- 3 satellite systems with $0.3 \mathrm{~m}$ of spatial resolution was used in order to obtain spectral and spatial information of buildings and roofs. For quality assessment, the physical and chemical parameters of the rooftop harvested rainwater were performed according to the Standard Tests for Water and Wastewater. The potential area for rooftop rainwater harvesting adoption can be identified with the detail information of the rooftops and quality assessment in geospatial environment.
\end{abstract}

\section{INTRODUCTION}

Rainwater is harvested from rooftops and ground surfaces as well as temporary watercourses. Rainwater can also provides affordable water for household uses and agriculture. Rooftop rainwater harvesting (RRWH) refers to the process of harvested water collection from rooftops (Gould and Nissen-Petersen, 1999). Through this system, Ojwang et al. (2017) stated that the system is capable to support the water supply at most area through water saving. Besides, this system also can be a key strategic adoption measures for communities affected by climate change.

Water management is a priority in development area whereby human population is expected to rise about $70 \%$ by 2050 (UN, 2012) with water must be accessible without compromising sustainability. Unfortunately, freshwater sources are becoming limited and polluted. These phenomena have become major public concerns. Therefore, rainwater harvesting systems have become popular means of conserving potable water. These systems are the most significant approaches for providing sustainable water cycles, particularly in urban development (Lee, Bak, and Han, 2012; Lye, 2009; Zhang et al., 2014). Rainwater collected from rooftops is assumed to be a relatively safe source of non-potable and potable water and regarded as non-polluted storm water. However, Zhang et al. (2014) revealed that the quality of rooftop harvested rainwater is significantly affected by roofing materials and the effects of these materials on water quality must be analysed carefully.

The types of roofing material used for the catchment can affect the quality of harvested rainwater (Carolina et. al., 2010). Most of the studies focused on examining conventional roofing materials such as galvanized metal for rainwater harvesting. Besides, long-term exposures to chemicals affected the harvested rainwater and cause numerous biological disorders. Despite the fact that many chemicals accumulate in living tissues over time, there are no reports concerning health risks associated with human contact, inhalation or ingestion of harvested rainwater that contaminated with chemical pollutants. This problem occurred due to the lack of local guidelines for specifying the range of physical and chemical parameters that suitable for both non-potable and potable applications of rooftop rainwater harvesting. Although non-potable applications may range from simple outside collection systems for irrigation of lawns and gardens to sophisticated residential uses such as toilet flushing and clothes laundering, each usage is subject to local scrutiny concerning the quality of rooftop harvested rainwater.

Segmentation technique in remote sensing leverage the advances in data acquisition with specific in terms of spectral and spatial resolution capability. High-resolution images contain rich texture information, which has been shown to improve segmentation results (Ryherd and Woodcock, 1996; Kim, Madden, and $\mathrm{Xu}, 2010)$. In image processing, a scale usually refers to the size of the operators or measurement probes used to extract information from image data. Improper scales can lead to over segmentation with segment corresponds to the portion of regions with one segment contains multiple landcover classes. Due to the inherent multiscale nature of realworld objects, many multiscale segmentation algorithms have been proposed (Tzotsos, Karantzalos, and Argialas, 2012; Johnson and Xie, 2011). However, manual interpretation is typically needed in order to utilize the segmentation results at multiple levels, which inevitably involve subjectivity. Moreover, it has been shown that, in specific cases, single-scale representation might be sufficient and more straightforward (Lang and Langanke, 2006).

GIS is capable to development the environmental model. From here, Mati et al., 2006 described GIS is a tool for collecting, storing, and analysing spatial and non-spatial data. Various thematic layers can be generated by applying spatial analysis with GIS software. The implementation of rooftop rainwater 
harvesting in urban area required specific studies in terms of data, analysis, and modelling.

This research aimed to develop the roofing layer with various information in order to determine the potential area for rooftop rainwater harvesting adoption at Taman Seri Serdang by using high resolution of satellite imagery and the results of quality assessment on the rooftop harvested rainwater.

\section{STUDY AREA}

The selected study area was in Taman Seri Serdang whereby this area was estimated with population of 14360 people by the Local Planning of Subang Jaya (Lim, Shaharuddin, Sam, 2012). In this area, there are residential area, commercial area and a secondary school with the estimated area is $0.2 \mathrm{~km}^{2}$. This study area is located at Seri Kembangan; which receiving $2600 \mathrm{~mm}$ of rain per year.

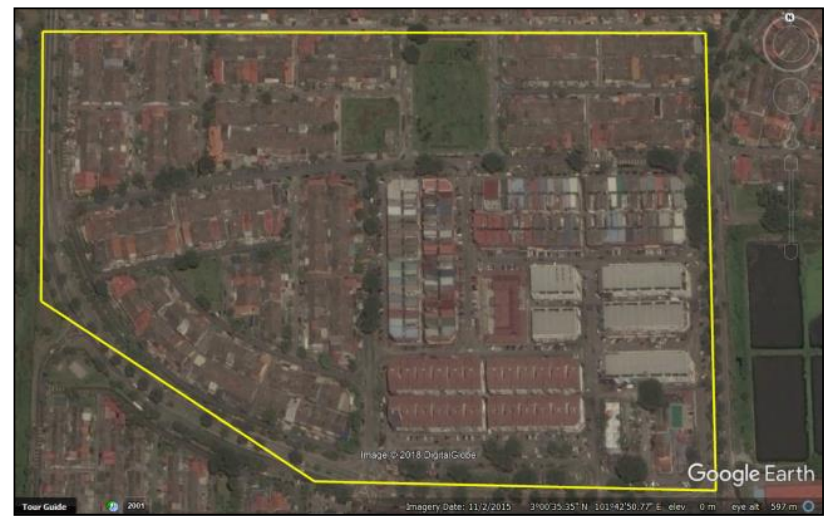

Figure 1: Study area at Taman Sri Serdang (Google Earth, 2018)

\section{METHODOLOGY}

In this study, roofing layer was developed from the building footprint and the result of quality assessment. The information needed in roofing layer are roofing materials, roofing conditions, roofing slope, physical and chemical parameters, and area of each rooftops.

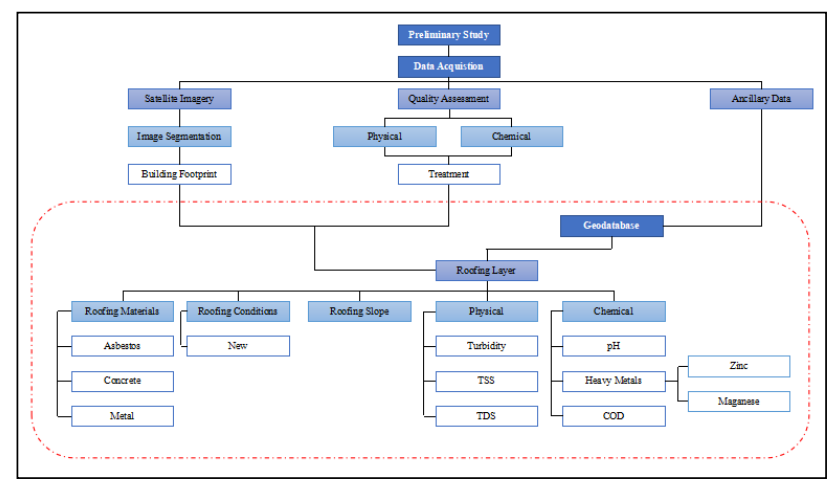

Figure 2: Methodology

\subsection{Image Segmentation}

Image segmentation was performed using eCognition software. Object Based Image Analysis (OBIA) is based on the human process of object recognition that required spectral value, shape, texture, and context information for image classification.
This technique is suitable for high resolution imagery with focusing on building extraction. In this study, Spectral Difference Algorithms was applied. This algorithm implied the concept of the neighbouring image objects are merged if the spectral difference is below the value given by the maximum spectral difference.

\subsection{Quality Assessment}

There are five types of roofing materials that were tested in this sudy; concrete, clay, zinc, polycarbonate, and asbestos. All of these roofs were set up with $20^{\circ}$ of slope. The rooftop harvested rainwater was flowed into first flush diverter until exceeding before being stored into the storage tanks. First flush diverters need to be incorporated into the system in order to protect the water quality in the collection tank from contamination (Abdulla and Al-Shareef, 2009; Gikas and Tsihrintzis, 2012). These prototypes were set up inside the Faculty of Engineering, Universiti Putra Malaysia whereby this faculty is next to Taman Seri Serdang.

The quality assessment was conducted based on physical and chemical parameters. For physical parameter, the rainwater properties such as colour, volume, and molecular weight were test without changing the chemical composition. In this testing, turbidity; the cloudiness of water samples and the tendency to transmit light properties in water, total suspended solid (TSS); the amount of filterable solids in the rainwater samples, and total dissolved solid (TDS); the amount of combination between organics and inorganic substances in water, are the physical parameters that being tested.

The assessment on the chemical parameter is based on the observation of any change on the chemical properties of a substances. In this assessment, $\mathrm{pH}$; the measurement of the potential activity of hydrogen ions $(\mathrm{H}+)$ in moles per liter in the rainwater samples, heavy metal with focusing on Zinc and Manganese, and Chemical Oxygen Demand (COD); the estimation of the capacity of water to consume oxygen during decomposition, are the chemical parameter for quality assessment.

\subsection{Development of Roofing Layer}

The roofing layer is based on the building footprint and the quality assessment. The building footprint was classified into building lot. With this classification, the attribute for this layer can be designed for each building lots.

This layer is done in ArcGIS software. The layer was registered into 2D coordinates projection. The attribute classes of this layer were classified into roofing materials, roofing conditions, roofing slope, and physical and chemical parameters. The area of each building lots was calculated using geometry. For the roofing materials and conditions; the identification is based on the satellite imagery.

\subsubsection{Satellite Imagery}

There are three types of roofing material were identified in the study area; concrete, metal, and asbestos with the roofing condition; either new or old. These assessment were done by the true colour combination of band 5, band 3, and band 2 of World-View 3 image. The assessment for roofing materials and roofing conditions are based on the pattern, texture, and colour of roofs in the satellite imagery. 


\section{RESULTS AND ANALYSIS}

Image segmentation using satellite imagery and quality assessment on rooftop harvested rainwater were performed according to the parameters. These results were used to develop the roofing layer.

\subsection{Building Footprint}

There are 764 of building lots were identified using segmentation method. The classification on roofing materials and roofing conditions were done based the pattern, texture and colour of the rooftops from the satellite imagery.

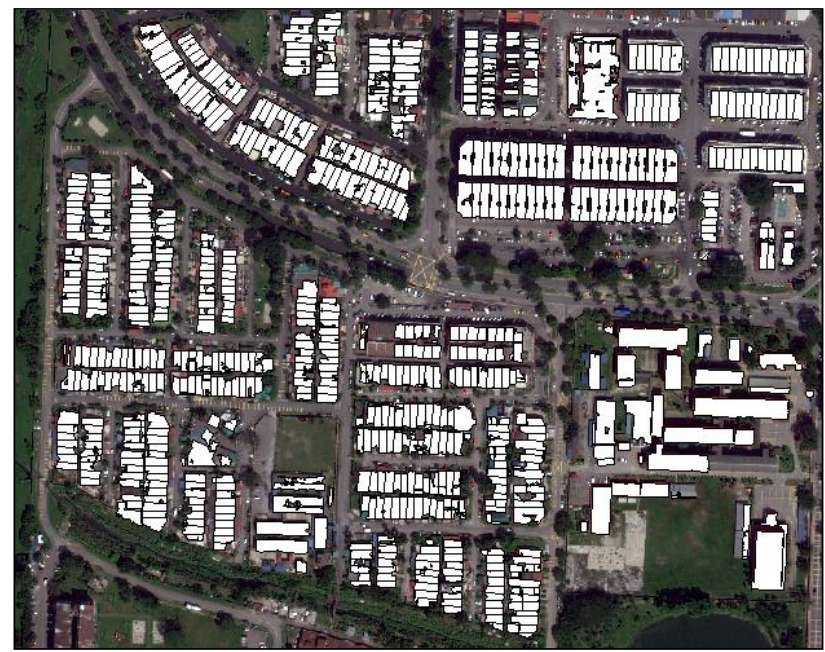

Figure 3: Building footprint at Taman Seri Serdang

\subsection{Quality Assessment}

The quality assessment of rooftop harvested rainwater was followed the Standard Water and Waste Water. The parameters used are in terms of physical and chemical. Then, the treatment of harvested rainwater were treated using coagulation and acidbased titration methods in order to remove colloidal impurities. Here, the results of water treatment were verified with the Drinking Water Quality Standard from the Ministry of Health Malaysia (2016). Based on the quality assessment, the rooftop harvested rainwater is suitable for non-potable water source with new metal is suitable to use in rooftop rainwater harvesting adoption.

\begin{tabular}{|c|c|c|c|c|c|c|c|c|}
\hline \multirow{2}{*}{$\begin{array}{l}\text { Roofing } \\
\text { Material }\end{array}$} & \multicolumn{8}{|c|}{ Chemical Parameter $(\mathrm{mg} / \mathrm{L})$} \\
\hline & $\mathrm{pH}$ & $\mathrm{QS}$ & \multicolumn{4}{|c|}{ Heavy Metal } & COD & QS \\
\hline & & & $\mathrm{Zn}$ & QS & $\mathrm{Mg}$ & QS & & \\
\hline Asbestos & 7.50 & $\begin{array}{c}5.5 \\
- \\
9.0\end{array}$ & 0.18 & 0.20 & $\begin{array}{c}0.000 \\
5\end{array}$ & 3 & 37.33 & 10 \\
\hline Concrete & 7.45 & $\begin{array}{c}5.5 \\
- \\
9.0\end{array}$ & 0.24 & 0.20 & $\begin{array}{c}0.000 \\
5\end{array}$ & 3 & 21.33 & 10 \\
\hline Metal & 6.93 & $\begin{array}{c}5.5 \\
- \\
9.0\end{array}$ & 1.37 & 0.20 & $\begin{array}{c}0.010 \\
0\end{array}$ & 3 & 26.67 & 10 \\
\hline
\end{tabular}

Table 1: Results of Chemical Parameters

\begin{tabular}{|l|c|c|c|c|c|c|}
\hline $\begin{array}{l}\text { Roofing } \\
\text { Material }\end{array}$ & \multicolumn{6}{|c|}{ Physical Parameter (mg/L) } \\
\hline Asbestos & Turbidity & QS & TSS & QS & TDS & QS \\
\cline { 2 - 7 } & 0.40 & $\begin{array}{c}100 \\
0\end{array}$ & 25 & N/A & 42 & 1500 \\
Concrete & 1.01 & $\begin{array}{c}100 \\
0\end{array}$ & $\begin{array}{c}32.6 \\
7\end{array}$ & N/A & 33.33 & 1500 \\
Metal & 0.76 & $\begin{array}{c}0 \\
0\end{array}$ & $\begin{array}{c}24.3 \\
3\end{array}$ & N/A & 36 & 1500 \\
\hline
\end{tabular}

Table 2: Results for Physical Parameters

Based on the comparison, the rooftop harvested rainwater is in good quality; in terms of physical. The TSS parameter is not listed in the standard. For chemical quality, further study should be carried out in terms of heavy metals (Zinc) and the COD.

\subsection{Development of Roofing Layer}

Roofing layer is based on the results of image segmentation; in terms of spatial data and the quality assessment for non-spatial data. The determination of roof materials and roof conditions basically from the satellite imagery. From here, 195 of building lots were identified as new condition of roof materials with 10 were identified as asbestos, 81 as metal, and 104 as concrete. These classification are labelled with colour; red colour for asbestos, yellow colour for concrete, and blue colour for metal. Each of building lots' area were calculated using geometry.

Next, the results from water treatment were tabulated according to the roofing materials. For roofing slope, all the building lots were assigned based on the parameter in the quality assessment.

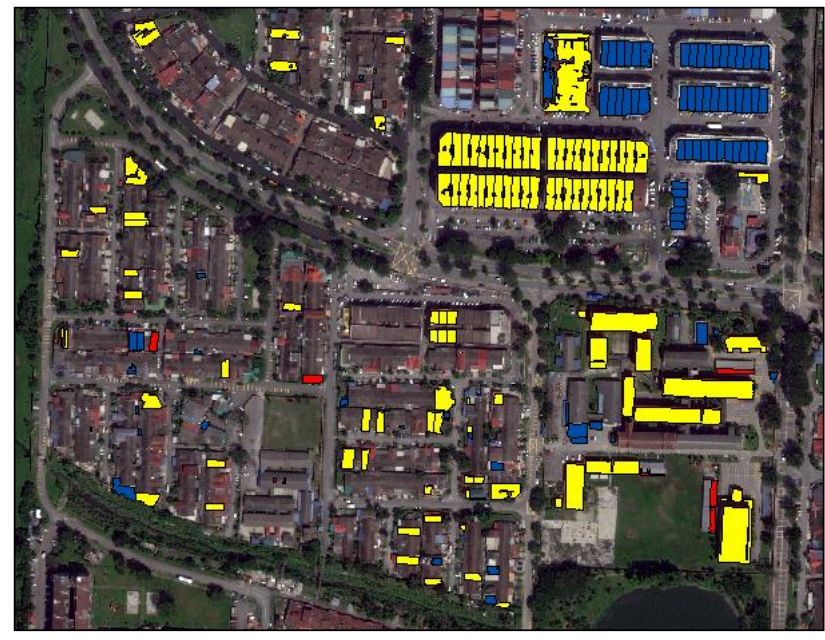

Figure 4: Roofing material with new condition

\section{CONCLUSION}

Roofing layer was developed with integration results from image segmentation and quality assessment. This is the initial step for the model development for rooftop rainwater harvesting for urban environment adoption. There are various elements that may affect the quality of rooftop harvested rainwater such as land use, rainfall variation, weather condition, and air quality. These parameters will lead to the model development by implementing sort of analysis such as geostatistical and spatial analysis; as part of GIS environmental study. 


\section{ACKNOWLEDGEMENTS}

This study was a part of the project titled "Development of an Integrated Remote Sensing and GIS Approach for Assessing Urban Environmental Impacts on the Quality of Rooftop Harvested Rainwater" funded by the Universiti Putra Malaysia. The authors acknowledged with the funding provided by UPM under the grant GPB/2017/9543100.

\section{REFERENCES}

Abdulla, F. \& Al-Shareef, A. (2009). Roof rainwater harvesting systems for household water supply in Jordan. Desalination. 243, 195-207.

Carolina, B. M., Brandon, K. J., Brigit, R. A., Mark, T. S., Michael, E. B., Kerry, A. K. \& Mary, J. K. (2010). The effect of roofing material on the quality of harvested rainwater. Water Research, Vol. 45, pp.2049-2059.

Engineering Services Division. (2016). Drinking water quality standard. Ministry of Health Malaysia. https://environment.com.my/wpcontent/uploads/2016/05/Drinking-Water-MOH.pdf

Gould, J. \& Nissen-Petersen, E. (1999). Rainwater catchment systems for domestic supply: design, construction and implementation. Intermediate Technology Publications, London, UK.

Johnson, B. \& Xie, Z. (2011). Unsupervised image segmentation evaluation and refinement using a multi-scale approach. ISPRS J. Photogramm. Remote Sens., Vol. 66, No. 4, pp. 473-483.

Kim, M., Madden, M., \& Xu, B. (2010). GEOBIA vegetation mapping in Great Smoky Mountains National Park with spectral and non-spectral ancillary information. Photogramm. Eng. Remote Sens., Vol. 76, No. 2,pp. 137-149

Lang, S. \& Langanke, T. (2006). Object-based mapping and object relationship modelling for land use classes and habitats. Photogramm., Fernerkundung, Geoinf., Vol. 10, No. 1, pp. 518.

Lee, J. Y., Bak, G., \& Han, M. (2012). Quality of roof harvested rainwater - Comparison of different roofing materials. Environmental Pollution, 162, 422-429.

Lim, C. S., Shaharuddin, M. S., \& Sam W. Y. (2012). Risk assessment of exposure to lead in tap water among residents of Seri Kembangan, Selangor state, Malaysia. Global Journal of Health Science. Vol. 5, No. 2.

Lye, D. J. (2009). Rooftop runoff as a source of contamination: A review. Science of the Total Environment, 407(21), 5429 5434. http://doi.org/10.1016/j.scitotenv.2009.07.011

Mati, B., De Bock, T., Malesu, M., Khaka, E., Oduor, A., Nyabenge, M., \& Oduor, V. (2006). Mapping the Potential of Rainwater Harvesting Technologies in Africa. A GIS Overview on Development Domains for the Continent and Ten Selected Countries. Technical Manual. 6, 126.

Ojwang, R. O., Dietrich, J., Anebagilu. P. K., Beyer., \& Rottensteiner, F. (2017). Rooftop rainwater harvesting for
Mombasa: scenario development with image classification and water resources simulation. Multidisciplinary Digital Publishing Institute. 9, 359.

Ryherd, S. \& Woodcock, C. (1996). Combining spectral and texture data in the segmentation of remotely sensed images. Photogramm. Eng. Remote Sens., Vol. 62, No. 2, pp. 181-194.

Tzotsos, A., Karantzalos, K., \& Argialas, D. (2011). Objectbased image analysis through nonlinear scale-space filtering. ISPRS J. Photogramm. Remote Sens., Vol. 66, No. 1, pp. 2-16.

United Nations. (2012). World urbanization prospects; the 2011 revision. Department of Economic and Social Affairs. Population Division. CD-ROM Edition.

Zhang, Q., Wang, X., Hou, P., Wan, W., Li, R., Ren, Y., \& Ouyang, Z. (2014). Quality and seasonal variation of rainwater harvested from concrete, asphalt, ceramic tile and green roofs in Chongqing, China. 'Journal of Environmental Management, 132, 178-187. https://doi.org/10.1016/j.jenvman.2013.11.009 